\title{
Hydronephrosis associated with ureteral wall thickness: Question
}

\author{
Meral Torun Bayram • Salih Kavukcu • \\ Mustafa Olguner • Ömer Ege • Alper Soylu • \\ Mehmet Turkmen
}

Received: 31 May 2012 /Revised: 12 June 2012 / Accepted: 12 June 2012 /Published online: 4 August 2012

(C) IPNA 2012

Keywords Hydronephrosis · Ureter · Acute kidney injury

\section{Case report}

A 12-year old male patient presented for elevated blood urea nitrogen and creatinine levels that were noticed during evaluation for anorexia, vomiting and weight loss for the preceding 2 weeks. Past medical history was characterized by right hydronephrosis determined 6 months ago upon evaluation for flank pain. At that time, although imaging tests had suggested suspicious right lower ureteral stone, cystoscopy had revealed fibrotic changes without stone in the lower right ureter. A temporary ureteral stent had been placed and removed during follow up.

Physical examination was normal apart from pallor. Laboratory tests revealed normal urinalysis, low hemoglobin $(8.5 \mathrm{~g} / \mathrm{dL})$, low MCV (74.5 fL), elevated acute phase response (erythrocyte sedimentation rate $54 \mathrm{~mm} / \mathrm{h}$, C-reactive protein $17.5 \mathrm{mg} / \mathrm{L}$ ), impaired renal functions (BUN $23 \mathrm{mg} /$ $\mathrm{dL}$, creatinine $2.34 \mathrm{mg} / \mathrm{dL}$, creatinine clearance $30 \mathrm{~mL} / \mathrm{min} /$ $1.73 \mathrm{~m}^{2}$, fractional $\mathrm{Na}$ excretion $3.6 \%$ ). Urinary system

The answer to this question can be found at http://dx.doi.org/10.1007/ s00467-012-2263-0.

M. T. Bayram $\cdot$ S. Kavukcu $\cdot$ A. Soylu $\cdot$ M. Turkmen Department of Pediatrics,

Dokuz Eylul University Medical Faculty,

Izmir, Turkey

\section{Olguner}

Department of Pediatric Surgery,

Dokuz Eylul University Medical Faculty,

Izmir, Turkey

\section{Ö. Ege}

Department of Urology, International Kent Hospital, Izmir, Turkey

\section{T. Bayram ( $\)$}

School of Medicine, Department of Pediatrics,

Dokuz Eylul University,

Izmir, Turkey

e-mail: meralt.bayram@yahoo.com.tr ultrasonography (USG) showed bilateral hydroureteronephrosis and increased renal echogenity. Magnetic resonance (MR) urography disclosed increased wall thickness in all segments of right ureter. Diagnostic ureteroscopy and retrograde pyelography revealed segmental areas of stenosis in both ureters (Fig. 1) and both ureters were catheterized. Renal functions were normalized shortly afterwards.

Diagnostic tests for the diseases associated with ureteral wall thickening including urine culture, PPD skin test, chest $\mathrm{X}$-ray, immunological tests for vasculitides and $M E F V$ gene mutation screening were normal.

\section{Question}

What would you do to diagnose the etiology of ureteral wall thickening at that point?

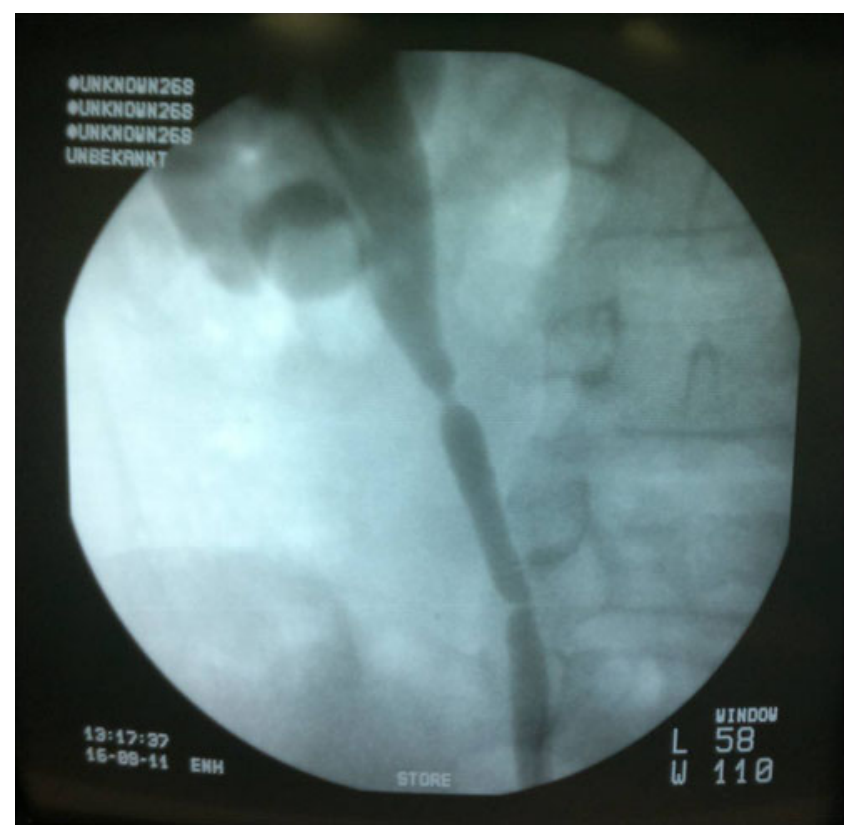

Fig. 1 Segmental areas of stenosis in the right ureter in retrograde pyelography 